\title{
Predicting Farmers' Willingness to Adopt Liquid Pollination and Polycarbonate Drying House Technologies: A Case Study from the Date Palm Growers in the Sultanate of Oman
}

\author{
Boubaker Dhehibi ${ }^{1}$, Mohamed Ben Salah ${ }^{2}$, Aymen Frija ${ }^{3}$, Aden Aw-Hassan ${ }^{1}$, Youssef M. Al Raisi ${ }^{4}$, Ibrahim Al \\ Bousaidi ${ }^{4}$, Suleiman Al Amri ${ }^{4}$, Said Al Sobahi ${ }^{4} \&$ Khaled Al Shoaili ${ }^{4}$ \\ ${ }^{1}$ Resilient Agricultural Livelihood Systems Program (RALSP), International Center for Agricultural Research in \\ the Dry Areas (ICARDA), El-Rawaby Neighborhood- Behind Abdallah Abu Ghosheh street, Yousef el sukkar \\ street bldg. no 8- Amman, Jordan \\ ${ }^{2}$ International Center for Agricultural Research in the Dry Areas (ICARDA), Directorate General of Agriculture \\ \& Livestock Research, Rumais, Barka, Muscat, Oman \\ ${ }^{3}$ Resilient Agricultural Livelihood Systems Program (RALSP), International Center for Agricultural Research in \\ the Dry Areas (ICARDA), 3, Rue Mahmoud Ghaznaoui, Menzah IV, 1082, Tunis, Tunisia \\ ${ }^{4}$ Date Palm Research Center, Directorate General of Agriculture \& Livestock Research, Rumais, Barka, Muscat, \\ Oman \\ Correspondence: Boubaker Dhehibi, Resilient Agricultural Livelihood Systems Program (RALSP), International \\ Center for Agricultural Research in the Dry Areas (ICARDA), El-Rawaby Neighborhood- Behind Abdallah Abu \\ Ghosheh street, Yousef el sukkar street bldg. no 8-Amman, Jordan. Tel: 962-065-920-120. E-mail: \\ b.dhehibi@cgiar.org
}

Received: February 27, 2018 Accepted: March 14, 2018 Online Published: July 30, 2018

doi:10.5539/sar.v7n4p18 URL: https://doi.org/10.5539/sar.v7n4p18

\begin{abstract}
The aim of this research paper is to assess the adoption level of the two technologies (liquid pollination and polycarbonate drying houses) in the Sultanate of Oman with emphasis on identifying influencing factors of the adoption process and exploring resulting policy implications. The methodological framework used is based on the implementation of the ADOPT (Adoption and Diffusion Outcome Prediction Tool) tool in two localities of the Sultanate of Oman through focus groups discussion (FGD's).

Empirical findings obtained from the assessment of the Liquid Pollination (LP) technology indicate that peak adoption rate for liquid pollination technology in "North Al Batinah" is high and predicted to be around $95 \%$ (of the total population) after a period of 14.5 years. The predicted adoption level after 5 and 10 years from introducing the technology in the region is estimated to be $46.9 \%$ and $91.5 \%$, respectively. The assessment of the rate of adoption of the Polycarbonate Drying Houses (PDH) technology and the identification of factors affecting the peak and adoption levels, and constraints that limit the adoption process and widespread of such technology among the date palm growers of Oman indicates that peak adoption rate for PDH technology in the target study region is predicted to be $95 \%$ after a period of 21 years. The predicted adoption level after 5 and 10 years is expected to be $23.5 \%$ and $72.9 \%$, respectively.

The presented results suggest that sustainable increase in date palm productivity can be achieved if farmers are encouraged to adopt the LP and PDH technologies. However, the adoption of such technology needs to be accompanied by a supporting extension system and an enabling policy environment to ensure the scaling-up and widespread use of these promising and profitable technologies.
\end{abstract}

Keywords: adoption, liquid pollination, polycarbonate drying houses, date palms, FGD's, ADOPT, Oman

\section{Introduction and Background}

Within the framework of the project "Development of sustainable date palm production systems in the GCC countries of the Arabian Peninsula", funded by the Gulf Cooperation Council (GCC) Secretariat, researchers succeeded to introduce two promising technologies: liquid pollination (LP) and polycarbonate drying houses (PDH). The aim to introduce LP technology is to improve the quality of fruits, reduce and save the time and 
effort during the pollination operation, reduce the risk of low fruit setting by pollination during the peak period of flowering, contribute to reducing harvesting losses. Therefore, the objective to introduce PDH technology is to improve the quality of dried dates, accelerate their drying process, and obtain cleaner fruits that are free from dust. The justification for solar driers is that they are more effective than sun drying traditional system (Mistah), with lower operating costs than mechanized drier.

These technologies have received a great deal of attention from the Government decision makers in recent years, but there is still no clear assessment of its current level and intensity of adoption, and the factors affecting its adoption. The success of both technologies will not only depend on how well from a technical perspective, but also on its affordability and profitability. The utilization and critical mass adoption of appropriate innovations is an important prerequisite for agricultural development, particularly in the Cooperation Council for the Arab States of the Gulf (GCC) countries in general and in the Sultanate of Oman, in particular.

The aims of this research paper is to assess the adoption level of the two technologies in the Sultanate of Oman with emphasis on identifying influencing factors of the adoption process and exploring resulting policy implications.

\section{Date palm sector in the Sultanate of Oman: Setting the Scene}

Date palm (Phoenix dactylifera L.) is a major fruit crop in the Arabian Peninsula, where it has been closely associated with the life of the people since pre-historic times. Date palm is a multipurpose tree used for food, feed, and fuel (firewood). It provides fiber, carbohydrates, minerals, and vitamins besides having certain medicinal properties (Al-Farsi et al., 2005; Al-Yahyai and Khan, 2015). In Oman, date palm is considered as the first agricultural crop, and it constitutes $80 \%$ of all fruit crops produced and represents about $50 \%$ of the total agricultural area in the country (FAO, 2013). Oman is the eighth largest producer of dates in the GCC countries and even in the world with an average annual production of 260,000 tons per year (FAO, 2013). There are approximately more than over seven million date palms and 250 cultivars in cultivation in the Sultanate. From the production point of view, around $70 \%$ of the total date production is harvested from only 10 cultivars, and a small fraction (2.6\%) of the total date production is exported. The literature assessment reveals that only half of the dates produced are used for human consumption, with the other half being utilized primarily for animal feed or considered surplus and wasted (Al-Yahyai and Khan, 2015).

According to Al-Marshudi (2002) and Al-Yahyai (2007), the yield of the date palm is considered to be low (40-80 kg/tree) compared to the yields in neighboring countries (i.e. Saudi Arabia and UAE). This low yield is a result of traditional management, lack of farmer know-how, high infestation by several pests, limited field expansion because date growing regions are fully dependent on groundwater extraction for irrigation, in addition to logistic problems, including an insufficient number of skilled laborers and underdeveloped facilities (transport, storage, market outlets, and large processing factories).

\section{Liquid Pollination Technology (LPT) in the Sultanate of Oman: An Appraisal}

\subsection{Characteristics of the LPT}

Pollination of date palm is normally carried out by hand in almost all date palm groves in Oman. Farmers are unaware of Liquid pollination, which may be easiest and most productive and convenient. According to Al-Yahyai and Khan (2015), there are several male palm cultivars that are used for pollination, most notably Khoori and Bahlani. El Mardi et al. (2002) reveals that pollinated varieties of date palm by hand, and using a hand duster and motorized duster with no effect on fruit yield, despite the larger fruit volumes when dusters were used. They also reported that a pollen/flour (1:5) ratio for mechanical pollination, used in Oman, produced lower sucrose and dry matter and a higher yield. In this regard, the project develops a new liquid pollination technology.

\subsection{Advantages of Using LPT}

The advantages of using LP technology in the Sultanate of Oman are as follows:

- Saves time and effort (reducing labor cost and improving the effectiveness and productivity of the labor used);

- Reduces the quantity of pollen needed;

- Reduces labor and pollen costs;

- Reduces the risk low fruit setting by pollinating during the peak period of flowering;

- Improves the quality of the fruits and consequently the profitability of the varieties intended for export;

- Contributes to reducing harvesting losses;

- Reduces the risk of climbing accidents to laborers. 


\subsection{Constraints of Using LPT}

With respect to the main constraints of using the LP could be as follows:

- No interest from the younger generation in date palm production;

- The pollination extraction device is expensive (around OMR3500), which small-scale farmers cannot afford;

- Limited number of date palm trees per farmer (the investment in the pollination extraction device is not profitable);

- Resistance of farmers to adopting the new technology and to changing their practices (farmers are accustomed to the old technology of hand pollination);

- Lack of specialized extension services for the date palm;

- Limited number of extension staff with massive responsibilities.

\subsection{Socio Economic Evaluation of LPT}

The intervention introduced by the project for the pollination of date palm trees was evaluated economically against the manual method for the Fardh cultivar based on the data collected from researchers and experts at the Date Palm Research Center, Experimental and Research Farm - Wadi Quriyat. In the findings reported in Dhehibi et al. (2016a), it was assumed that the yield would be maintained the same using the two options (LP technology and manual pollination). The premise that even if the quantity produced of dates is slightly reduced using liquid pollination, the weight of fruit will increase - given the advantage of a decreased proportion of the fruit setting and concomitant increase in the quality of the fruit. In this case, it was considered as natural fruit thinning. This improvement in the quality will affect the market price and for that, it was considered a higher price for the dates produced using liquid pollination. From this research study, it was found that a reduction in pollination cost using liquid pollination was observed in comparison to that for manual pollination of about $89.05 \%$ and, consequently, a reduction in the total variable costs per hectare against those for manual pollination of about $56.48 \%$.

Moreover, the analysis revealed a total reduction in the variable costs of OMR1273.95 from using liquid pollination. This reduction in total variable costs results from an increase in the net revenue over that resulting from manual pollination of OMR2593.95/ha. Economic indicators showed also the clear profitability of using liquid pollination where the percentage change in net returns is very high $(+674.71 \%)$. The benefit-cost ratio $(\mathrm{BCR})$ is three times higher when using liquid pollination. Thus, with an internal rate of return of 12.04 and higher BCR, it was concluded that liquid pollination will be highly profitable for Omani farmers.

From the same study, it was reported also that similar results were achieved from the data obtained from farmers for the Khalas cultivar. With the same assumptions on yield and related price-quality, it was found that an increase in the value of production of about $20 \%$ from using liquid pollination rather than the manual pollination. The analysis showed that using liquid pollination reduced the pollination operation costs by $89.05 \%$ (which is the equivalent of OMR1273.95/ha) compared to traditional pollination. The reduction in pollination induces a reduction in the total variable costs of $22.10 \%$. Economic analysis results revealed also that the net benefit to date palm farmers, using the cultivar Khalas, and applying liquid pollination was OMR15,310.5/ha (an increase of around $42.60 \%$ compared to manual pollination). The analysis of the Internal Rate of Return (IRR) indicates that investment in liquid pollination technology is a profitable decision. Generally, using LP will yield a cost-benefit ratio that reaches 3.41, which is almost twice the ratio, obtained from using manual pollination.

\section{Polycarbonate Drying House for Date Palm Products (PDH) Technology in the Sultanate of Oman: An Assessment}

\subsection{Characteristics of the PDH for Date Palm Products}

The PDH dryer is a unique cost efficient method of drying agricultural products such as date palm products at commercial scale. It consists of a drying chamber and an exhaust fan. Transparent plastic films that are mounted on a metal frame make the roof and the wall of a PDH.

Shahi et al. (2011) found that the solar drier sheet has a transmissivity of approximately $92 \%$ for visible radiation, which traps the solar energy during the day and maintains an optimum temperature for drying of produce. In addition, the authors indicated that UV-stabilized films play an important role in PDH dryers. The UV radiation in the sunrays tends to cause changes in the organoleptic properties such as texture, color and flavor of food materials (Shahi et al., 2011). From technical characteristics, UV-stabilized polyethylene sheets used to prevent such deterioration, and consequently the sheet allows only short wavelength, which is converted into long wavelength when it raids on the surface of the dried product. Since the long wavelength cannot move out, it 
increases the temperature inside the dryer. In addition to the outlined advantages mentioned above, the sheet has superior properties in terms of transparency, transmissivity, property, anti-corrosion, tensile properties, tear-resistant, anti-puncture, waterproof, moisture proof, and dust-proof.

According to Janjai et al. (2011), polycarbonate covers have been used recently for PDH construction. Contrary to the polycarbonate, plastic sheets and glass covers have the distinct property to allow light to enter the PDH dryer and retaining it inside the chamber, the heating mechanism is as black surface inside the PDH improves the effectiveness of converting light into heat. Hence, the objective of a PDH dryer is to maximize the utilization of solar radiation. Based on the mode of heat transfer, the technology is classified into passive and active PDH dryers. The passive mode dryer works on the principle of thermosyphic effect i.e. the moist air is ventilated through the outlet provided at the roof of the dryer (Janjai et al., 2011).

Sangamithra et al. (2014) showed that trapped light is converted into heat energy to remove moisture from dates in the PDH dryer. The dryer can be connected in series, hence its capacity can be enhanced as per requirement, and it can be dismantled so that its transportation is easy from one place to another. Prakash and Kumar (2014) study suggests that two energy sources namely the air saturation deficit and the incident global solar radiation are used to active the PDH dryer. They indicated that both natural and forced convection methods circulate the hot air to the food material.

\subsection{Advantages of Using the PDH for Date Palm Products}

The principal advantages on using the PDH technology are the following:

- Improves the quality of the fruits, especially in humid areas;

- Avoids the contamination of dates by insects, birds, dust, and rain;

- Accelerates the drying process;

- Reduces the loss rate;

- Could be used for other purposes (e.g. drying other products, such as fish).

\subsection{Constraints to Using the PDH for Date Palm Products}

Although the high range of advantages on using the PDH technology, some constraints or limitations still exist and could be as follows:

- High initial investment cost (needs to be subsidized by the government);

- Concerns over the impact of heat on the quality of product (transfer of the plastic material);

- Farmers lack knowledge on the maintenance of the system;

- Not profitable for date palm growers with very small holdings;

- Lack of extension agents specialized in date palm.

\subsection{Socio Economic Viability of PDH for Date Palm Products}

The traditional methods used in Oman for drying dates under direct sunshine called "Mustah" is a slow process with problems like dust contamination, insect infection, bad quality of fruits, and spoilage due to unexpected climatic changes. To overcome this problem, one of the main objectives of the "Development of Sustainable Date Palm Production Systems in GCC" project is to produce new knowledge and practices to improve date palm production systems in the Gulf region.

Other alternative options are available to overwhelm the problem such as the use of conventional fuel fired or electrically operated dryers. However, in many rural areas, the supply of electricity is not available or it is too expensive and could not be affordable by the small date palm growers for drying purpose. Moreover, the fossil fuel fired dryer's technology possesses several financial barriers due to large initial investment and operational running cost which are beyond the reach of small farmers. The main objective if introducing this technology by this development project was to improve the quality of dried dates, accelerate their drying process, and obtain cleaner fruits that are free from dust. This technology is considered one of the most attractive and promising applications of solar energy systems in the GCC countries can be utilized in date palm production areas as a better alternative to dehydrate the date and other agricultural products without any difficulties. Also from environmental perspective, the use of PDH can result in reduced emissions if conventional fuel is replaced.

The implementation of this improved technology can have positive socioeconomic impacts on local income generation, food security and consequently a sustainable date palm farming system. In the practice, Chavada (2009) found that the lifetime cost of drying with solar power is only a third of the cost of using a dryer based on conventional fuels. According to Janjai et al. $(2009,2011)$, the price of dates dried in PDH was found to be $20 \%$ higher than that obtained from the open sun drying. The estimated payback period (PBP) of the former 
technology was 2.3 years. Dhehibi et al. (2016b) found that a PDH dryer could function successfully and efficiently with minimum maintenance at low cost.

With no further disadvantages, it could be a substitute to the conventional dryers thereby making it assessable and affordable by local farmers in the Omani date palm producers. In this study, PDH dryer for dates were evaluated economically for two types (small vs large PDH) under two scenarios: with and without governmental subsidies. Empirical findings reveal the high profitability of the PDH, even when the government does not subsidize it. At a real discount rate of $5.1 \%$, the net present value (NPV) is positive and very high in all cases. Thus, such an investment is usually acceptable if the NPV is positive, (the investment is profitable). This criterion was also supported by both the IRR and the PBP criteria (Figures 1-4).

\section{Cumulative Cash Flow at Year End}

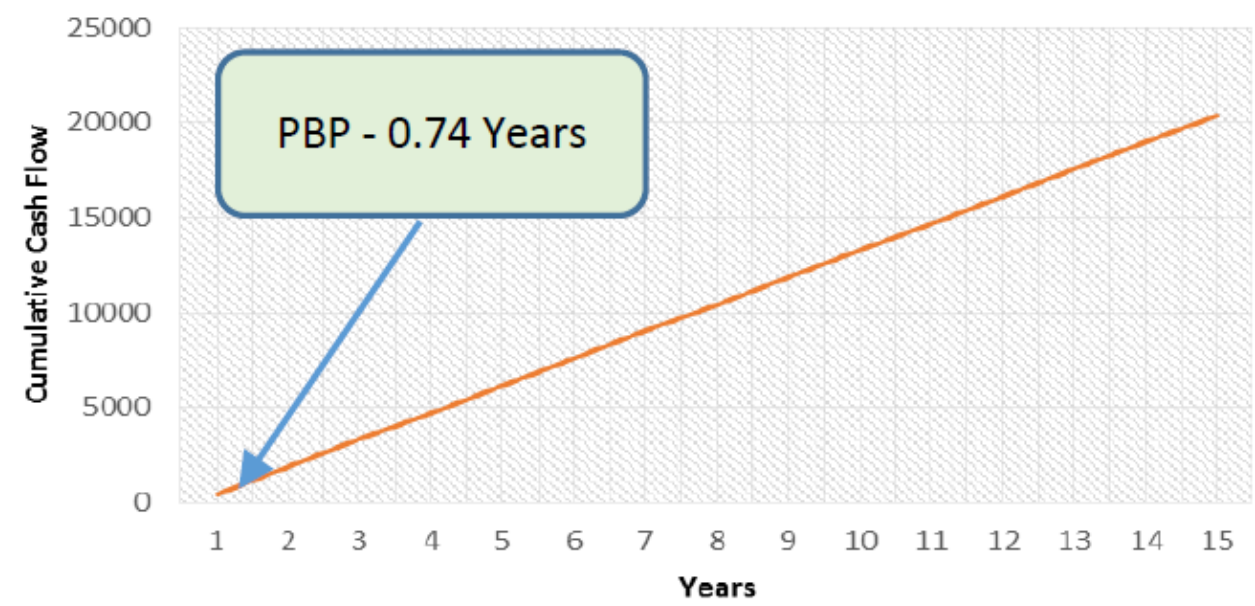

Figure 1. Cumulative Cash Flow at end of year (PBP when the small PDH subsidized)

Source: Dhehibi et al., (2016b).

\section{Cumulative Cash Flow at Year End}

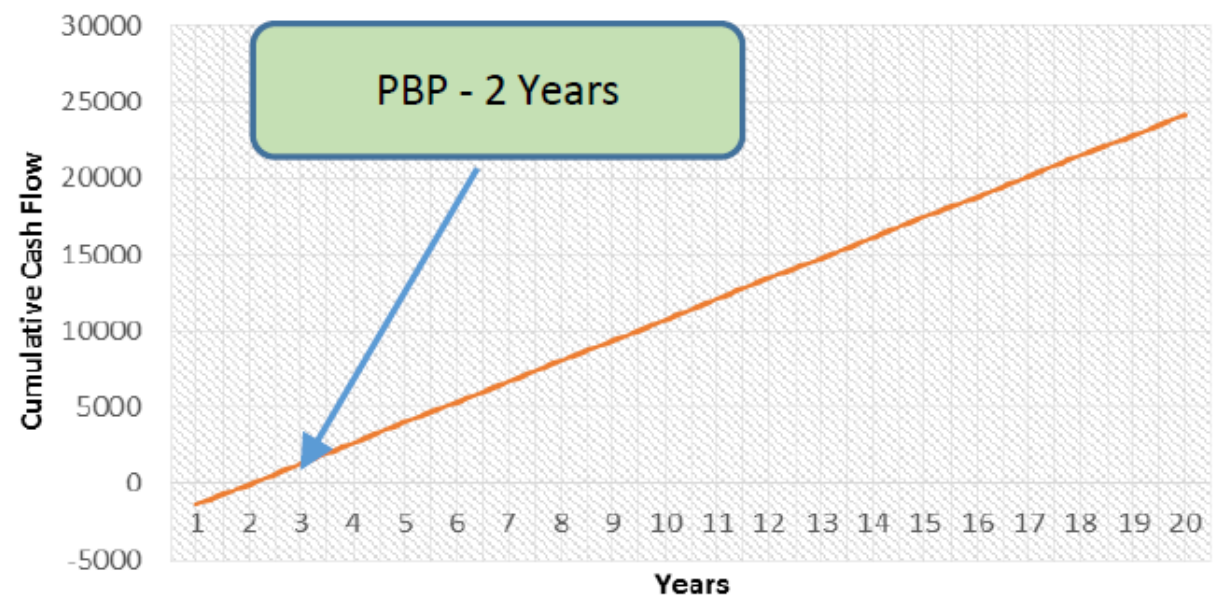

Figure 2. Cumulative Cash Flow at end of year (PBP when the large PDH subsidized)

Source: Dhehibi et al., (2016b).

The estimated IRR was higher than the current interest rate in the Sultanate, which could encourage both date palm growers and private investors to invest in polycarbonate drying houses. The PBP figure was found, in the worst-case scenario, to be 3.77 years, which is relatively short considering the life of the system (15-20 years). This suggests that investment or action costs in this dryer system are recovered quickly reducing the risk involved in the investment. 


\section{Cumulative Cash Flow at Year End}

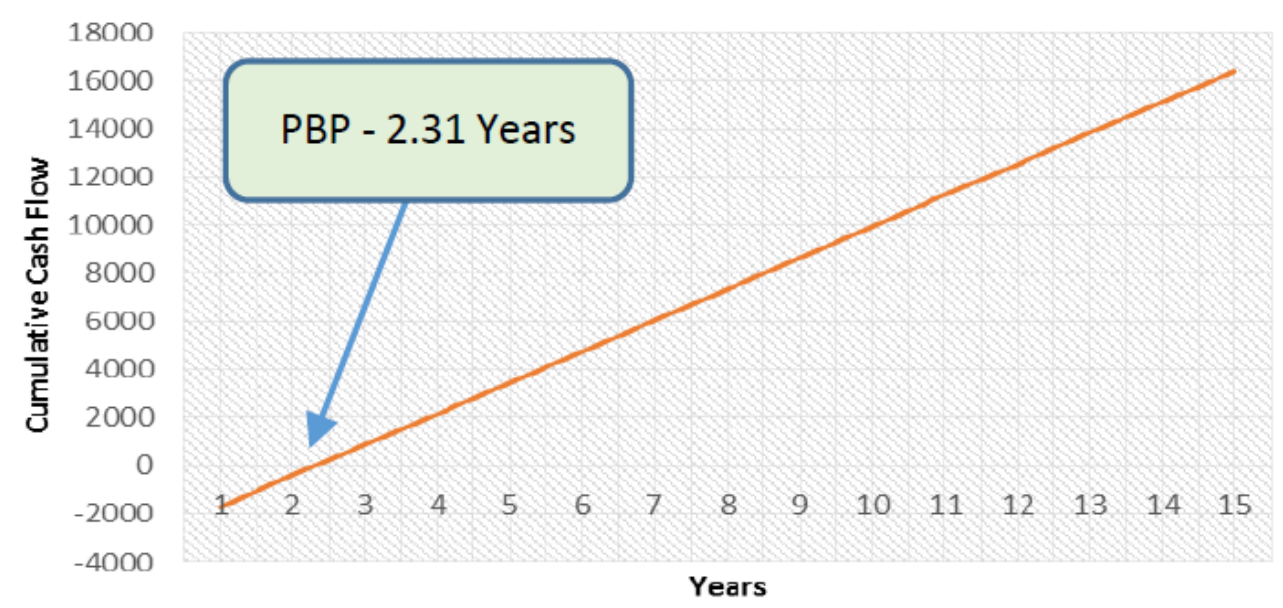

Figure 3. Cumulative Cash Flow at end of year (PBP when the small PDH is not subsidized)

Source: Dhehibi et al., (2016b).

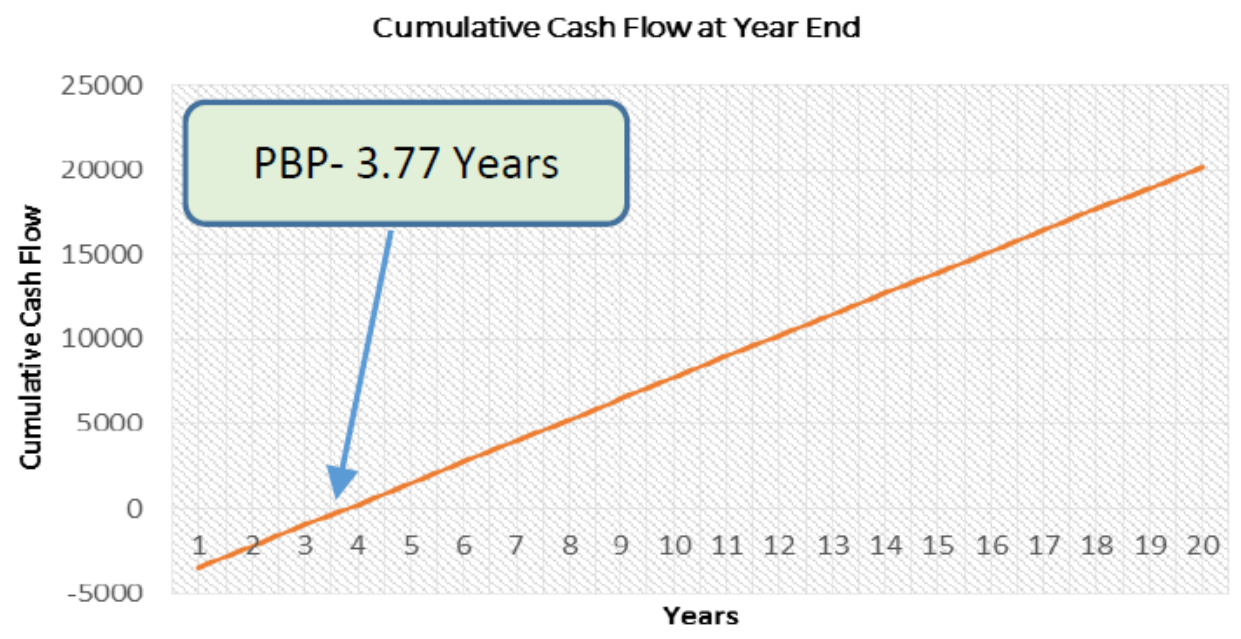

Figure 4. Cumulative Cash Flow at end of year (PBP when the large PDH is not subsidized)

Source: Dhehibi et al., (2016b).

\section{Adoption Assessment of LP and PDH Technologies in the Sultanate of Oman}

\subsection{Conceptual Framework}

The adoption of new agricultural technologies has generally been found to be a function of farm and farmer characteristics and specific features of the particular technology (Feder et al., 1985; Marra and Carlson, 1987; Rahm and Huffman, 1984). A considerable set of research documents was developed regarding factors affecting the adoption of new agricultural technologies by farmers through use of innovation theory (Feder et al., 1985; Griliches, 1957, and Rogers, 1995). In addition, adoption and diffusion theory also have been widely used to identify factors that influence an individual's decision to adopt or reject an innovation. In this regards, Rogers (1995) defined an innovation as "...an idea, practice or object that is perceived as new by an individual or other unit of adoption. The perceived newness of the idea for the individual determines his or her reaction to it". Five characteristics of an innovation have been identified and could affect an individual's adoption decision:

- (i) Relative advantage: how the innovation is better than existing technology;

- (ii) Compatibility: the degree to which an innovation is seen as consistent with existing experiences, needs, and beliefs of adopters;

- (iii) Complexity: how difficult the innovation is to understand and use; 
- (iv) Trialability: the degree to which the innovation may be used on a limited basis; and

- (v) Observability: the degree to which the results of an innovation are visible to others.

The relative advantage and observability of an innovation represents the immediate and long-term economic benefits from using it, whereas compatibility, complexity, and trialability indicate the ease with which a potential adopter can learn about and use an innovation (Boz and Akbay, 2005; King and Rollins, 1995). As the relative advantage, compatibility, complexity, trialability, and observability of liquid pollination and polycarbonate drying house have caused more farmers to adopt them in the GCC countries, in general and, in the Sultanate of Oman, in particular, we can consider the adoption of the two technologies as an innovation. The utilization and critical mass adoption of such technologies is an important prerequisite for agricultural development, particularly for the date palm producing countries in the Arabian Peninsula.

\subsection{Methodological Framework: Adoption Analytical Model: Adoption and Diffusion Outcome Prediction Tool (ADOPT) (Note 1)}

ADOPT is an MS Excel-based tool that evaluates and predicts the likely level of adoption and diffusion of specific agricultural innovations for particular target population. The tool uses expertise from multiple disciplines to make the knowledge about adoption of innovations more available, understandable and applicable to researchers, extension agents and research managers. ADOPT predicts the proportion of a target population that might adopt an innovation over time (Figure 5).

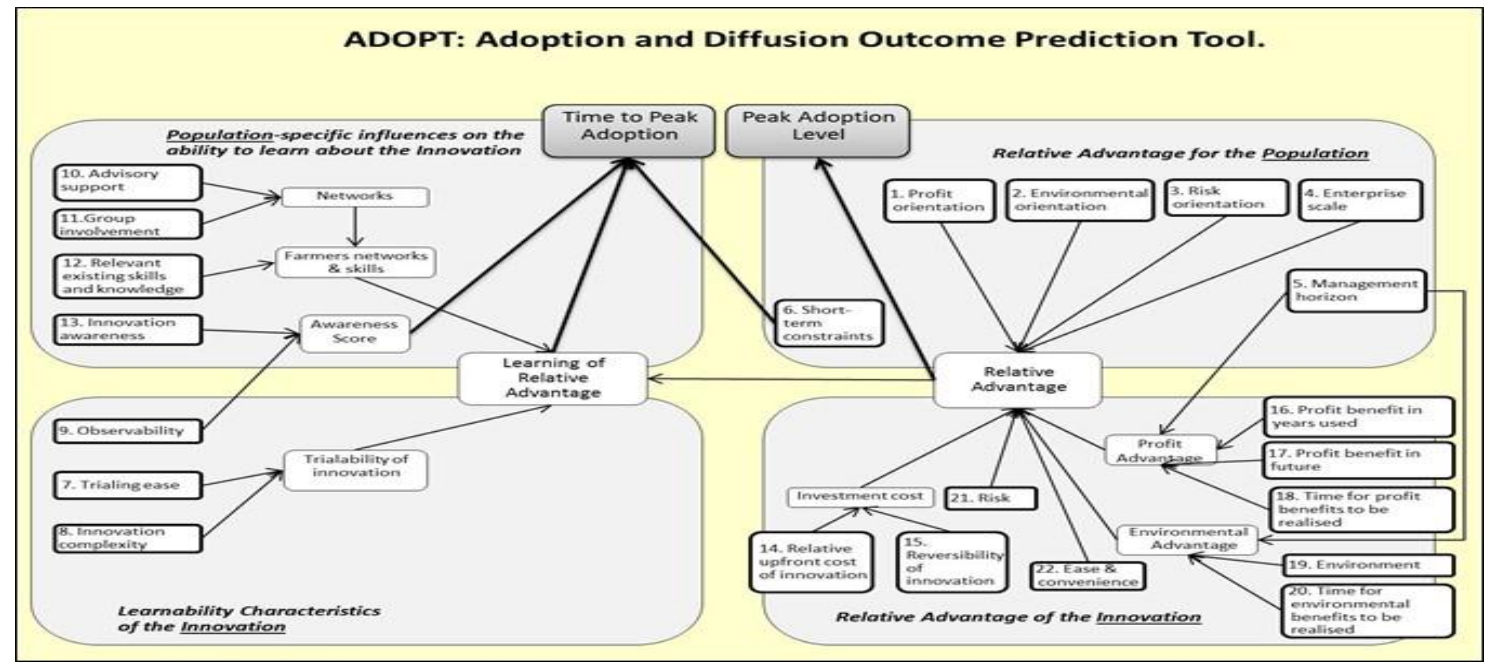

Figure 5. Adoption and Diffusion Outcome Prediction Tool (ADOPT)

Source: http://aciar.gov.au/files/node/13992/adopt_a_tool_for_evaluating_adoptability_of_agric_94588.pdf.

The tool makes the issues around the adoption of innovations easy to understand. ADOPT is useful for agricultural research organizations and people interested in understanding how innovations are taken up.

The tool has been designed to:

1. Predict the likely peak level of adoption of an innovation and the time taken to reach that peak.

2. Encourage users to consider the factors that affect adoption at the time that projects are designed.

3. Engage research, development and extension managers and practitioners by making adoptability knowledge and considerations more transparent and understandable.

ADOPT users respond to qualitative and quantitative questions for each of twenty-two variables influencing adoption. Going through this process also leads to increased knowledge about how the variables relate to each other, and how they influence adoption and diffusion. ADOPT framework is structured around four categories of influences on adoption (Figure 5 above): (1) Characteristics of the innovation; (2) Characteristics of the target population; (3) Relative advantage of using the innovation; and (4) Learning of the relative advantage of the innovation.

\subsection{Data Collection and Data Sources}

The study took place in two governorates in the Sultanate of Oman (South and North Al Batinah) characterized 
by an extensive date palm production and the common testing of the liquid pollination technology and implementation of the polycarbonate drying houses. The data were collected using focus group discussion (FGD) methodology (Krueger, 2002) to apply the ADOPT tool (Kuehne et al., 2013) with a group of farmers in the two Governorates. To assess the liquid pollination technology, we interviewed 24 date palm growers divided in two equal FGD's, each covering 12 farmers'. For the polycarbonate drying house technology, a different group of ten (10) farmers have been interviewed. The study took place in the two governorates during January 2017.

We also organized a FGD with Ministry technical staffs representing both Agricultural Development Centers. All of them were males. One researcher from the Omani Date Palm Research Centre, the date palm project manager and the socio economic leader of the project economic activities from the International Center for Agricultural Research in the Dry Areas (ICARDA: http://www.icarda.org) conducted the FGD's with farmers. In the two cases, we streamlined 22 discussion questions around four categories of influences on adoption. The format of the discussion group consisted of both analytical questions (i.e., they discuss and collectively decide what they believe the answer is), and clarifying questions (i.e., questions that help clearing up confusion and explain why they had chosen this answer). Farmers have been asked to think about their problems related to implementing liquid pollination and the most challenging for them.

\section{Results and Discussion}

\subsection{Factors Influencing Adoption Level and Time to Peak Adoption Level of LP Technology}

The issue of this technology adoption by agricultural producers has not been assed. This study has generally focused on the technology adoption processes at the firm level and on identifying the main factors affecting its adoption process. The results of the program predicted that $95 \%$ of the South and North Al Batinah Communities would adopt the innovations after 16.9 and 14.5 years, respectively (Table 1).

Table 1. Predicted Adoption Levels of LPT at North and South Al Batinah - Sultanate of Oman

\begin{tabular}{lll}
\hline Predicted Peak Level and Time of LP Adoption & $\begin{array}{l}\text { North Al Batinah } \\
\text { Governorate }\end{array}$ & $\begin{array}{l}\text { South Al Batinah } \\
\text { Governorate }\end{array}$ \\
\hline Predicted years to peak adoption & 14.5 & 16.9 \\
Predicted peak level of adoption & $95 \%$ & $95 \%$ \\
Predicted adoption level in 5 years from start & $46.9 \%$ & $35.8 \%$ \\
Predicted adoption level in 10 years from start & $91.5 \%$ & $85.8 \%$ \\
\hline
\end{tabular}

Source: Own elaboration from ADOPT (2017).

Note: Focus groups (\# 12 farmers).

As displayed in the table above, the peak adoption rate for liquid pollination technology in the "North Al Batinah" is predicted to be $95 \%$ after a period of 14.5 years. The predicted adoption level in 5 years and 10 years from start is expected to be $46.9 \%$ and $91.5 \%$, respectively. In "South Al Batinah" Governorate, the predicted adoption levels are similar. Indeed, the predicted years to peak adoption is 16.9 years and the peak level of adoption is around $95 \%$. This peak is predicted to be $35.8 \%$ and $85.8 \%$ after 5 and 10 years from start, respectively.

Results from the sensitivity analysis (Figures 6 \& 7) indicates that farmers' conditions of severe short-term financial constraints, the trialability of the innovation on a limited basis before a decision is made to adopt it on a larger scale, the perception and evaluation of the liquid pollination technique; i.e. how the innovation allow the effects of its use to be easily evaluated when it is used, the paid advisory delivery system, the development of substantial new skills and knowledge to use the innovation by the farmers, and finally the size of the up-front cost of the investment relative to the potential annual benefit from using the innovation are the driving adoption factors for the liquid pollination technology in the two targeted areas. 


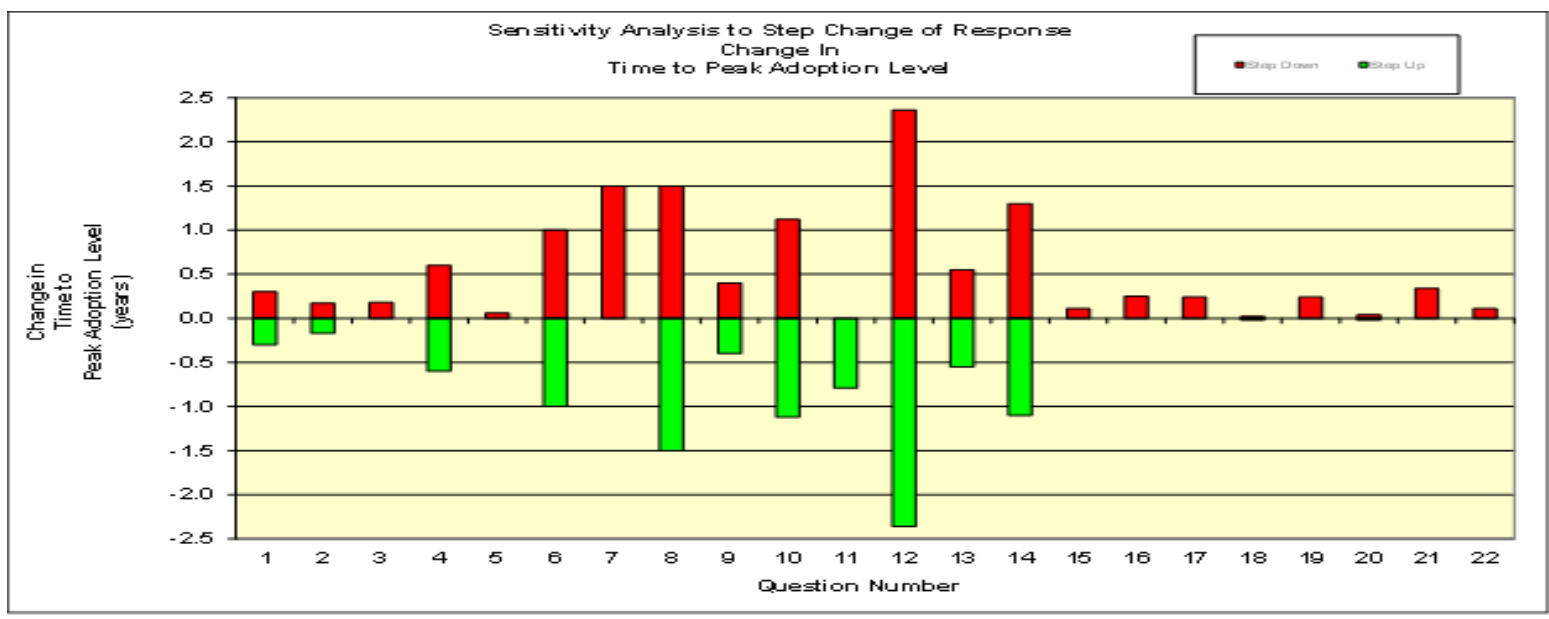

Figure 6. Sensitivity Analysis of Adoption Curve of LPT at "North Al Batinah" Governorate - Sultanate of Oman Source: Own elaboration from ADOPT (2017).

Note 1: Red Column: Step Down; Green Column: Step Up.

Note 2: Focus groups (\# 12 farmers).

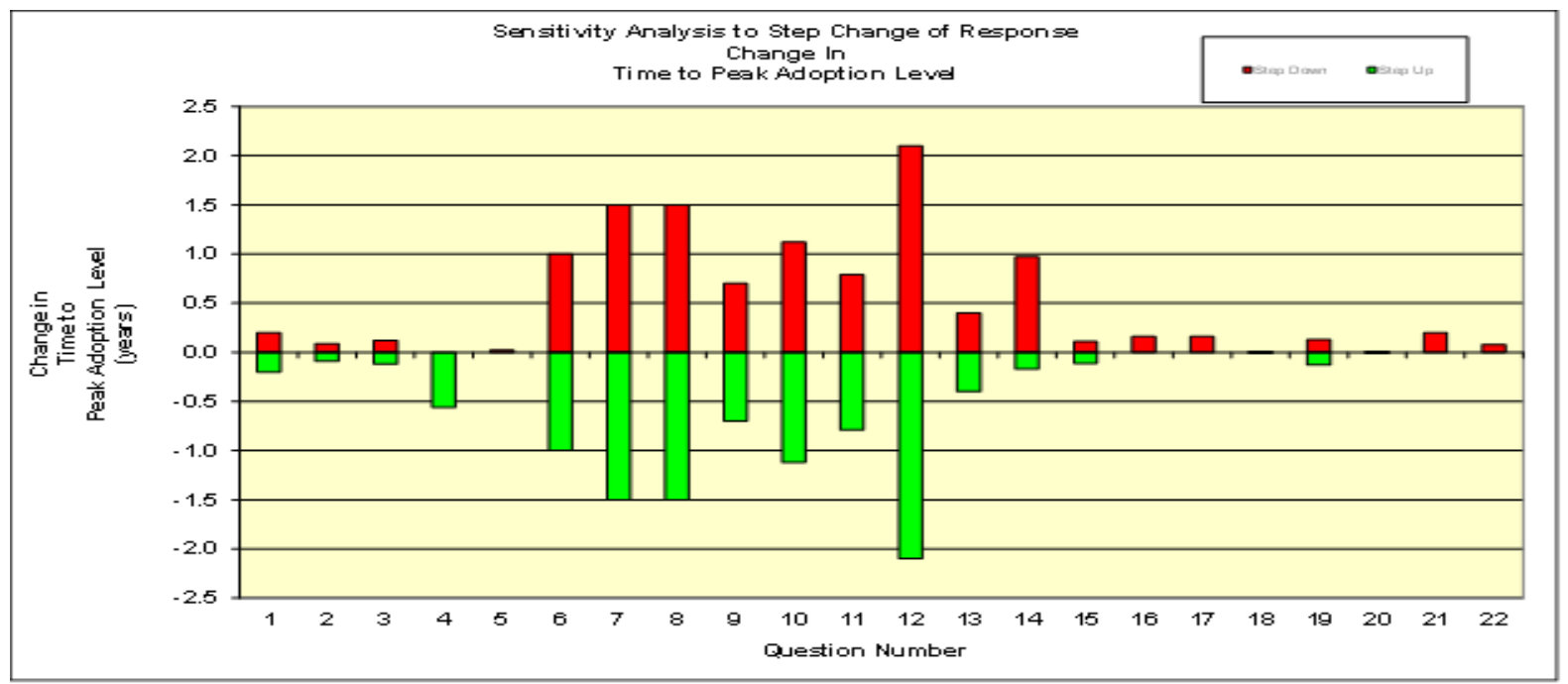

Figure 7. Sensitivity Analysis of Adoption Curve of LPT at "South Al Batinah" Governorate - Sultanate of Oman Source: Own elaboration from ADOPT (2017).

Note 1: Red Column: Step Down; Green Column: Step Up.

Note 2: Focus groups (\# 12 farmers).

\subsection{Factors Influencing Adoption Level and Time to Peak Adoption Level of PDH Technology}

The predicted years to peak adoption and the predicted adoption level, including the level in 5 and 10 years from start, is presented in Table 2. Even though adoption and diffusion of the PDH dryer is very difficult to forecastthe issue is complex and crosses economic, social and psychological disciplines - there is an ongoing need and demand for specific estimates to be made.

Empirical findings from the table below revealed that $95 \%$ of "South Al Batinah" Community would adopt the innovations after 20.9 years. However, the predicted adoption levels after 5 and 10 years from start is $23.5 \%$ and $72.9 \%$, respectively. Even though the time to peak adoption was longer than what we expected (bearing in mind that this figure affected the attractiveness of the technology in the future funding), these results are expected since the upfront cost of investment is quite high while the economic viability of this technology make the 
evidence of its profitability. Indeed, the outcomes from this tool could be considered as real values to inform the different stakeholders about the influences on adoption and diffusion of the PDH technology in Oman.

Table 2. Predicted Adoption Levels of PDH Technology at "South Al Batinah" Governorate - Sultanate of Oman

\begin{tabular}{ll}
\hline Predicted Peak Level and Time of PDH Adoption & South Al Batinah Governorate \\
\hline Predicted years to peak adoption & 20.9 \\
Predicted peak level of adoption & $95 \%$ \\
Predicted adoption level in 5 years from start & $23.5 \%$ \\
Predicted adoption level in 10 years from start & $72.9 \%$ \\
\hline
\end{tabular}

Source: Own elaboration from ADOPT (2017).

Note: Focus groups (\# 10 farmers).

After presenting these indicators, the FGD's outputs discussion outlined that farmer's most commonly cited motivations for adopting this technology although the high upfront cost of investment. Our study and FGD's discussion found that both adopters and non-adopters saw the greatest benefits of this technology in terms of its potential benefit on the quality of the final agricultural dried products (dates, in this case). Another assessment framework to better understand the factors associated the rapid and large adoption of the PDH technology was by conducting a sensitivity analysis. Important factors to farmer decision making differ according to geographic, economic, and social context.

Figure 8: Sensitivity Analysis of Adoption Curve of PDH Dryer Technology at the "South Al Batinah" Governorate - Sultanate of Oman

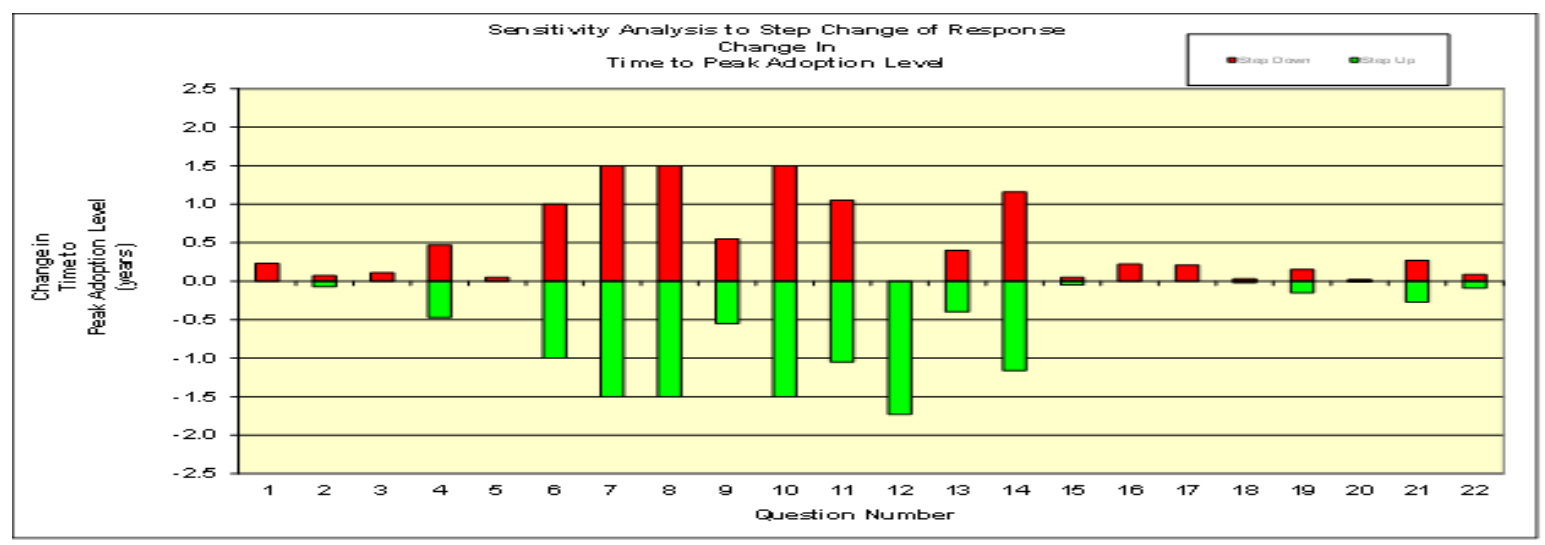

Source: Own elaboration from ADOPT (2017).

Note 1: Red Column: Step Down; Green Column: Step Up.

Note 2: Focus groups (\# 10 farmers).

However, taken together, the results from the sensitivity analysis regarding the main factors affecting the adoption decision of PDH technology in AL Batinah Governorate are displayed in Figure 8. The figure content indicates that trialability of the innovation on a limited basis before a decision is made to adopt it on a larger scale, the perception and evaluation of the PDH technique; i.e. how the innovation allow the effects of its use to be easily evaluated when it is used, the paid advisory delivery system capable of providing advice relevant to the use and management of the technology, and finally the size of the up-front cost of the investment relative to the potential annual benefit from using the innovation are the driving adoption factors for the PDH technology in the target area.

\section{Concluding Remarks and Policy Implications}

The objective of this paper is to analyze the main factors affecting the predicted adoption level, the peak to reach 
this level, and the constraints of adoption of LP and PDH technologies introduced by the date palm project in the sultanate of Oman. The methodological framework used was based on the implementation of the ADOPT tool to focus groups of date palm growers in two localities of the Sultanate. In the FGD we streamlined 22 discussion questions around four categories of influences on adoption: characteristics of the innovation, characteristics of the target population, relative advantage of using the innovation and learning of the relative advantage of the innovation.

The empirical findings obtained from the liquid pollination technology assessment indicates that peak adoption rate for liquid pollination technology in "North Al Batinah" is predicted to be $95 \%$ after a period of 14.5 years. The predicted adoption level in 5 years and 10 years from start is expected to be $46.9 \%$ and $91.5 \%$, respectively. In "South Al Batinah" Governorate, the predicted adoption levels are similar. Indeed, the predicted years to peak adoption is 16.9 years and the peak level of adoption is around $95 \%$. This peak is predicted to be $35.8 \%$ and $85.8 \%$ in 5 and 10 years from start, respectively. The assessment of the rate of adoption of the PDH technology and the identification of factors affecting the peak and adoption levels, and constraints that limit the adoption process and widespread of such technology among the date palm growers of Oman indicates that peak adoption rate for PDH technology in the target study region is predicted to be $95 \%$ after a period of 21 years. The predicted adoption level after 5 and 10 years is expected to be $23.5 \%$ and $72.9 \%$, respectively.

The presented results suggested that sustainable increases in productivity of date palm in the Sultanate of Oman could be achieved if farmers are encouraged to adopt the liquid pollination and polycarbonate drying chambers technologies. However, the adoption of such technology needs to be accompanied by a supporting extension system and an enabling policy environment to ensure the scaling-up and widespread use of this promising and profitable technology. Such findings can provide a useful framework for decision-making as date palm producers and policy makers confront sustainable date palm farming system. In addition, the results can facilitate the policy formulation process as policy makers, responding to societal pressures, attempt to move date palm farming system in a more sustainable direction while trying to improve the profitability of the sector, in general. Implications could be derived for producers for whom local environmental quality is closely linked to date palm production systems in Oman. The results from the present research study suggest the following:

- Creation of private service companies to carry out and monitor the LP operations. These companies can even be operated by small farmers in order to diversify their income sources;

- Enhancing the extension services (more and specialized extension agents) and the development of an effective extension service for Omani date palm growers;

- Reinstatement of the subsidy system in the sector;

- Creation of private services and marketing companies with support from the government;

- Enhancing the awareness of farmers regarding the profitability of using this technology in comparison to the manual pollination method;

- Development of an agricultural management program for date palm tree services, the application of quality control measures, and an increase in capacity building to reduce the cost of production;

- Make introducing the technology to the responsibility of the government; it cannot be left to farmers;

- Valorization of the date palm by-products (to generate more profit for the date palm producers).

- Polycarbonate projects should targeted high levels date palm productions areas.

\section{Acknowledgment}

We would like to express our sincere gratitude and appreciation to the Gulf Cooperation Council (GCC) Secretariat for funding this research conducted in the framework of the "Development of sustainable date palm production systems in the GCC countries of the Arabian Peninsula" project. We are very grateful to the Ministries of Agriculture, Agricultural Authorities, and Agricultural Research Institutions and Universities in the GCC countries of the Arabian Peninsula for their continuous support and great collaboration in the implementation of the project activities.

\section{Declarations of conflict of interest}

The authors report no declarations of conflict of interest.

\section{References}

Al-Farsi, M., Alasalvar, C., Morris, A. et al. (2005). Comparison of antioxidant activity, anthocyanins, carotenoids, and phenolics of three native fresh and sun-dried date (Phoenix dactylifera $\mathrm{L}$.) varieties grown in Oman. Journal of Agricultural and Food Chemistry, 53, 7592-7599. https://doi.org/10.1021/jf050579q

Al-Marshudi, A. S. (2002). Oman traditional date palms: production and improvement of date palms in Oman. 
Tropicultura, 20(4),203-209.

Al-Yahyai, R. (2007). Improvement of date palm production in the Sultanate of Oman. Acta Horticulturae, 736, 337-343. https://doi.org/10.17660/ActaHortic.2007.736.32

Al-Yahyai, R., \& Khan, M. M. (2015). Date palm and perspective in Oman. Pages 207-240. In Date Palm Genetic Resources and Utilization: Volume 2: Asia and Europe (J.M. Al-Khayri, S.M. Jain, and D.V. Johnson eds). Springer, Dordrecht, Heidelberg, New York, London.

Boz, I., \& Akbay, C. (2005). Factors influencing the adoption of maize in Kahramanmaras province of Turkey. Agricultural Economics, 33, 431-440. https://doi.org/10.1111/j.1574-0864.2005.00305.x

Dhehibi, B., Aw-Hassan, A., Ben Salah, M., Al Raisi, Y., Al Bousaidi, I., Al Amri, S., \& Al Sobahi, S. (2016a). Economic comparison and evaluation of manual and liquid pollination methods of date palm trees in the Sultanate of Oman (varieties Fardh and Khalas). ICARDA Technical Report, 11p.

Dhehibi, B., Aw-Hassan, A., Ben Salah, M., Al Raisi, Y., Al Bousaidi, I., Al Amri, S., Al Shoaily, K. (2016b). Economic evaluation of a polycarbonate drying house for date palm products. ICARDA Technical Report, $10 \mathrm{p}$.

El Mardi, M. O., Esechie, H., AI-Kharousi, L. M., \& Abdelbasit, K. M. (2002). Effect of pollination method on changes in physical and chemical characteristics of date fruit during development. Agricultural Science, 7(1), 21-27.

Food and Agriculture Organization of the United Nations (FAO) (2011). FAOSTAT. Crop Production, Statistics Division, FAO, Rome. Retrieved from http://www.faostat.fao.org. Accessed March 2017.

Food and Agriculture Organization of the United Nations (FAO) (2014). FAOSTAT. Crop Production, Statistics Division, FAO, Rome. Retrieved from http://www.faostat.fao.org . Accessed March 2017.

Griliches, Z. (1957). Hybrid corn: An exploration in the economics of technological change. Econometrica, 25, 501-522. https://doi.org/10.2307/1905380

Janjai, S., Lamlert, N., Intawee, P., Mahayothee, B., Bala, B., Nagle, M. (2009). Experimental and simulated performance of a PV-ventilated solar greenhouse dryer for drying of peeled longan and banana. Sol Energy, 83, 1550-1565. https://doi.org/10.1016/j.solener.2009.05.003.

Janjai, S., Intawee, P., Kaewkiew, J., Sritus, C., \& Khamvongsa, V. (2011). A large-scale solar greenhouse dryer using polycarbonate cover: modeling and testing in a tropical environment of Lao People's Democratic Republic. Renewable Energy, 36, 1053-1062. https://doi.org/10.1016/j.renene.2010.09.008

King, R., \& Rollins, T. (1995). Factors influencing the adoption of a nitrogen-testing program. Journal of Extension, 33(4). Retrieved from http://www.joe.org/joe/1995august/rb2.php.

Krueger, R. A. (2002). Analysis: Systematic Analysis Process. Retrieved from http://www.tc.umn.edu/ rkrueger/focus_analysis.html.

Kuehne, G., Llewellyn, R., Pannell, D., Wilkinson, R., Dolling, P., \& Ouzman, J. (2013). ADOPT: the Adoption and Diffusion Outcome Prediction Tool (Public Release Version 1.0, June 2013) [Computer software] Adelaide SA; CSIRO. Retrieved from http://www.csiro.au/ADOPT

Marra, M., \& Carlson, G. (1987). The role of farm size and resource constraints in the choice between risky technologies. Western Journal of Agricultural Economics, 12(2), 109-118.

Ministry of Agriculture and Fisheries (MAF) (2015). Annual report. MAF, Muscat, Sultanate of Oman.

Oman - Statistical Yearbook (2015). Issue 43. Retrieved from https://www.ncsi.gov.om/Elibrary/Pages/LibraryContentDetails.aspx?ItemID=lffQDcPJGNjEE5Xix4WK2g $\% 3 \mathrm{D} \% 3 \mathrm{D}$.

Prakash, O., \& Kumar, A. (2014). Solar greenhouse drying: a review. Renewable and Sustainable Energy Reviews, 29, 905-910. https://doi.org/10.1016/j.rser.2013.08.084

Rahm, M., \& Huffman, W. (1984). The adoption of reduced tillage: The role of human capital and other variables. American Journal of Agricultural Economics, 66(4), 405-413. https://doi.org/10.2307/1240918

Rogers, E. (1995). Diffusion of innovations (4th ed.). New York: The Free Press.

Sangamithra, A., John Swamy, G., Prema, R.S., Priyavarshini, R., Chandrasekar, V., \& Sasikala, S. (2014). An overview of a polyhouse dryer. Renewable and Sustainable Energy Reviews, 40, 902-910. 
https://doi.org/10.1016/j.rser.2014.08.007.

Shahi, N. C., Khan, J. N., Lohani, U. C., Singh, A., \& Kumar, A. (2011). Development of polyhouse type solar dryer for Kashmir valley. Journal of Food Science Technology, 48, 290-295. https://doi.org/10.1007/s13197-010-0172-4

\section{Notes}

Note 1. All information concerning how ADOPT works is found at:

http://aciar.gov.au/files/node/13992/adopt_a_tool_for_evaluating_adoptability_of_agric_94588.pdf.

\section{Copyrights}

Copyright for this article is retained by the author(s), with first publication rights granted to the journal.

This is an open-access article distributed under the terms and conditions of the Creative Commons Attribution license (http://creativecommons.org/licenses/by/3.0/). 